\title{
BLyS and APRIL in rheumatoid arthritis
}

\author{
Thorsten M. Seyler, ${ }^{1}$ Yong W. Park, ${ }^{1}$ Seisuke Takemura, ${ }^{1}$ Richard J. Bram, ${ }^{2}$ \\ Paul J. Kurtin, ${ }^{3}$ Jörg J. Goronzy, ${ }^{1}$ and Cornelia M. Weyand ${ }^{1}$
}

\author{
1Department of Medicine, Lowance Center for Human Immunology, Emory University School of Medicine, Atlanta, Georgia, USA. \\ ${ }^{2}$ Department of Pediatrics and Adolescent Medicine and ${ }^{3}$ Department of Pathology, Mayo Clinic, Rochester, Minnesota, USA.
}

\begin{abstract}
The cytokines B lymphocyte stimulator (BLyS) and a proliferation-inducing ligand (APRIL) enhance autoimmune disease by sustaining $B$ cell activation. In RA, B cells contribute to the formation of 3 functionally distinct types of lymphoid microarchitectures in the inflamed synovium: ectopic GCs; T cell-B cell aggregates lacking GC reactions; and unorganized, diffuse infiltrates. We examined 72 tissues representing the 3 types of synovitis for BLyS and APRIL production and for expression of APRIL/BLyS receptors. Biologic effects of BLyS and APRIL were explored by treating human synovium-SCID mouse chimeras with the APRIL and BLyS decoy receptor transmembrane activator and CAML interactor:Fc (TACI:Fc). $\mathrm{GC}^{+}$synovitis had the highest levels of APRIL, produced exclusively by $\mathrm{CD83}^{+} \mathrm{DCs}$. BLyS was present in similar levels in all tissue types and derived exclusively from $\mathrm{CD}^{+} 8^{+}$macrophages. In $\mathrm{GC}^{+}$synovitis, treatment with TACI:Fc resulted in GC destruction and marked inhibition of IFN- $\gamma$ and Ig transcription. In contrast, inhibition of APRIL and BLyS in aggregate and diffuse synovitis left Ig levels unaffected and enhanced IFN- $\gamma$ production. These differential immunomodulatory effects correlated with the presence of $\mathrm{TACI}^{+} \mathrm{T}$ cells in aggregate and diffuse synovitis and their absence in $\mathrm{GC}^{+}$synovitis. We propose that BLyS and $\mathrm{APRIL}$ regulate $\mathrm{B}$ cell as well as $\mathrm{T}$ cell function and have pro- and antiinflammatory activities in RA.
\end{abstract}

\section{Introduction}

RA is a systemic autoimmune disease that primarily targets the synovial membrane, cartilage, and bone. Synovial inflammatory infiltrates typically include T cells, B cells, macrophages, and DCs that arrange in defined microarchitectures. The organization of tissue-infiltrating lymphocytes in the synovium is highly complex and recapitulates molecular pathways of lymphoid organogenesis $(1,2)$. A typical example of ectopic lymphoid neogenesis is the formation of GCs in the synovial sublining layer. Such synovial GCs support B cell selection and affinity maturation (3). In contrast to GC reactions in lymphoid organs, synovial GCs depend upon a unique population of $\mathrm{CD}^{+} \mathrm{T}$ cells positioned in the mantle zone that colocalize with lymphotoxin$\beta$-producing (LT- $\beta$-producing) B cells (4). Synovial T cells and B cells can also arrange in clusters, called $\mathrm{T}$ cell-B cell aggregates, which lack central follicular DCs (FDCs), B cell proliferation, and mantle zone formation. Recent cohort studies have revealed that $\mathrm{GC}^{+}$and aggregate ${ }^{+}$tissues are present in similar frequencies and account for about $50 \%$ of all patients. The other half of patients has diffuse $\mathrm{T}$ and $\mathrm{B}$ cell infiltrates without distinct topographic arrangements, a pattern called diffuse synovitis (5).

A close correlation exists between the lymphoid architecture and the functional activity of T cells and B cells in the lesion (6). The sharing of T cell receptor sequences between distinct GCs strongly suggests the sharing of antigens (7). However, an antigen-independent pathway may also influence B cell recruitment, organization, and functional activity in rheumatoid synovitis. Recent reports indicate that $\mathrm{B}$ cell activation, differentiation, and survival are determined

Nonstandard abbreviations used: APRIL, a proliferation-inducing ligand; BAFF-R, $\mathrm{BAFF}$ receptor; BCMA, B cell maturation antigen; BLyS, B lymphocyte stimulator; CD21L, CD21 long isoform; FDC, follicular DC; LT, lymphotoxin; SLE, systemic lupus erythematosus; SS, Sjögren syndrome; TACI, transmembrane activator and CAML interactor.

Conflict of interest: The authors have declared that no conflict of interest exists.

Citation for this article: J. Clin. Invest. 115:3083-3092 (2005).

doi:10.1172/JCI25265. not only by antigen and $\mathrm{T}$ cell interaction, but also by cytokines, particularly by members of the TNF ligand superfamily (8).

The TNF superfamily member B lymphocyte stimulator (BLyS), also referred to as BAFF, THANK, TALL-1, TNFSF13b, and zTNF4 (9-12), is known to be a very effective modulator of peripheral B cell homeostasis that promotes B cell survival and differentiation (13). BLyS is expressed by a few stromal cells, $\mathrm{T}$ cells, and most myeloid cell lineages - including monocytes, macrophages, DCs, and stimulated neutrophils - and may be the active cytokine by which macrophages and DCs regulate human B cell function (14-18). BLyS transgenic mice show an expansion of the peripheral mature B cell compartment, hyperglobulinemia, anti-single-stranded DNA and anti-double-stranded DNA antibodies, and circulating immune complexes. Such mice develop autoimmune-like manifestations reminiscent of human systemic lupus erythematosus (SLE) and Sjögren syndrome (SS) $(19,20)$. Consistent with those data, elevated BLyS serum levels have been found in patients with RA, SLE, and SS (21-24). In contrast, in $\mathrm{BLyS}^{-/-}$mice, B cell development in the spleen is impaired beyond the $\mathrm{T} 1$ transitional stage and in the peritoneum beyond the $\mathrm{B} 1$ stage. There are practically no T2, marginal zone, or follicular B cells in the spleen and lymph nodes or B2 cells in the peritoneum present, indicating that BLyS is fundamental for B cell homeostasis. Along with diminished B cell differentiation, serum Ig levels are profoundly reduced (13).

A proliferation-inducing ligand (APRIL), also known as TALL-2, TRDL-1, and TNFSF13a $(25,26)$, is a close homolog to BLyS that is expressed by monocytes, macrophages, DCs, T cells, and several types of tumor cells. APRIL is virtually undetectable in normal tissues but is strongly expressed in adenocarcinomas and can accelerate the growth of malignant cells in vitro and in vivo. In contrast to most ligands of the TNF superfamily that are known to be homotrimers, APRIL and BLyS have also been reported to form heterotrimeric molecules when coexpressed, and those APRIL/ BLyS heterotrimers are present in the serums of patients with systemic autoimmune diseases like RA, SLE, and SS (27). Mice 
A
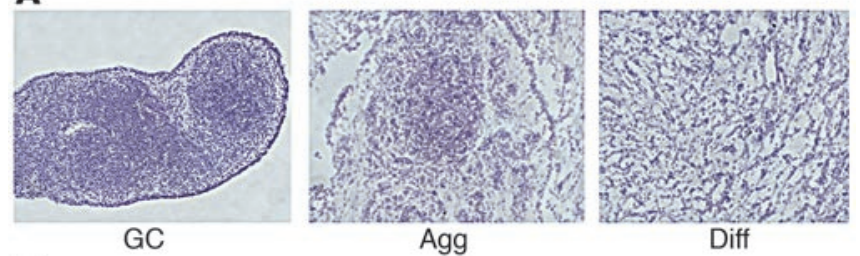

B
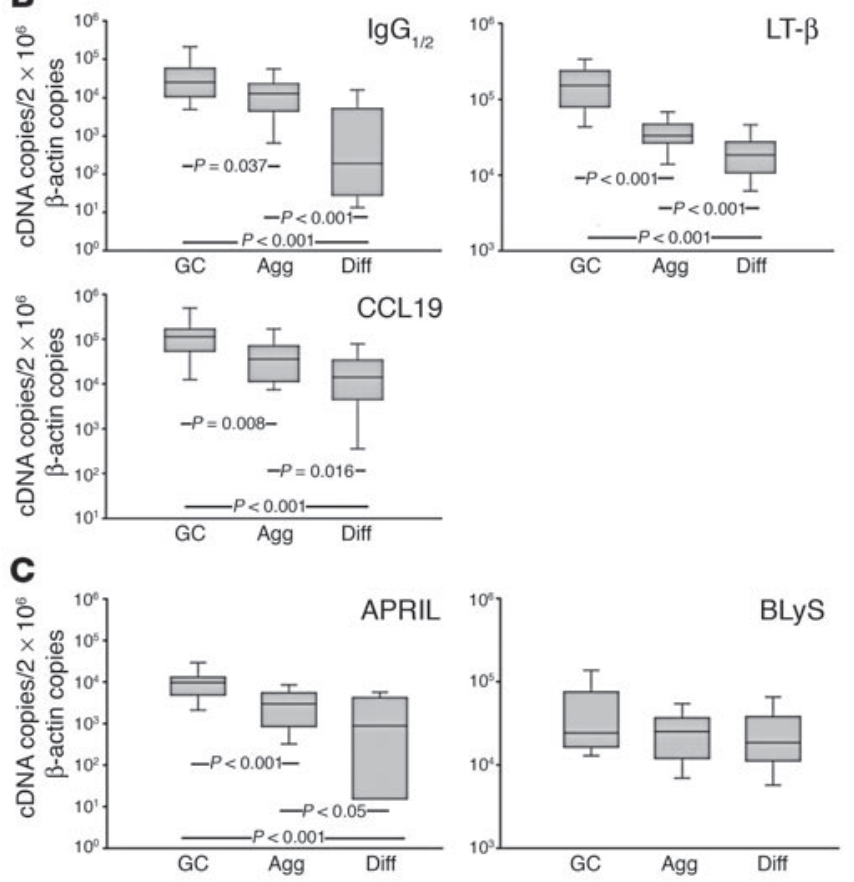

expressing APRIL as a transgene demonstrate normal B cell development with no signs of B cell hyperplasia. APRIL overexpression promotes a strong survival signal for both $\mathrm{CD}^{+}$and $\mathrm{CD}^{+} \mathrm{T}$ cells in vivo. $T$ cell-dependent humoral responses revealed an increase in serum IgM, while serum IgG levels remained unaffected. T cell-independent type II humoral responses were also enhanced, manifested by elevated IgM and IgG serum levels (28). In contrast, $\mathrm{APRIL}^{-/-}$mice present with normal development, maturation, distribution, and function of T and B lymphocytes (29).

Like other members of the TNF superfamily, APRIL and BLyS share receptors and bind specifically to 2 TNF superfamily receptors, transmembrane activator and CAML interactor (TACI; also known as TNFRSF13b) and B cell maturation antigen (BCMA). In addition, BLyS binds exclusively to a third TNF family receptor, BAFF receptor (BAFF-R) $(30,31)$.

TACI is expressed on mature B cells and on activated T cells (32). In TACI:Fc transgenic mice, fewer transitional T2 and mature B cells have been found. In addition, TACI:Fc overexpression leads to a decrease in circulating IgG levels, a loss of B1 cells in the peritoneum, and a significant decrease in the number of $\mathrm{CD}^{+}$and $\mathrm{CD}^{+} \mathrm{T}$ cells in the spleen and mesenteric lymph nodes (33). In contrast, $\mathrm{TACI}^{-/-}$mice develop fatal lymphoproliferation, splenomegaly, B cell accumulation with increased Ig production, B cell lymphoma, and SLE-like autoimmune disease with anti-nuclear and anti-double-stranded DNA autoantibodies, suggesting that TACI is an inhibitory receptor. It has also been reported that $\mathrm{T}$ cell-dependent and T cell-independent type I humoral responses

\section{Figure 1}

B cell function and tissue expression of APRIL/BLyS in RA synovium. Synovial biopsies from 72 patients were classified according to the lymphoid microarchitectures. Sixteen patients had GC+ synovitis, 30 patients had aggregate synovitis, and 26 patients had diffuse synovitis. cDNA from tissue extracts was adjusted relative to $2 \times 10^{6} \beta$-actin copies, and specific transcripts were determined by real-time PCR. (A) $\mathrm{H} \& \mathrm{E}$ staining of representative tissues displayed classical GC (left), lymphoid aggregates (Agg) without GC formation (middle), and diffuse (Diff) mononuclear infiltrates without topographical clustering (right). Original magnification, $\times 100$. (B) IgG transcription was highest in $\mathrm{GC}^{+}$ synovitis, intermediate in aggregate synovitis, and low in diffuse synovitis. LT- $\beta$ and CCL19 production correlated closely with the pattern of lymphoid organogenesis in the synovium. (C) Tissue transcripts for APRIL followed the same hierarchy as LT- $\beta$ and CCL19. BLyS-specific sequences were abundantly found in all tissues with no correlation to synovial lymphoid microstructures. Results are shown as box plots with medians, twenty-fifth and seventy-fifth percentiles as boxes and tenth and nintieth percentiles as whiskers. $P$ values are indicated where statistically significant.

in TACI knockout mice appear normal, while T cell-independent type II humoral responses are defective (34-36).

Considering the critical role of B cells in rheumatoid synovitis, we sought to determine whether APRIL and BLyS sustain B cell function in the tissue lesions, providing a T cell-independent mechanism of autoimmunity. For these studies we have exploited the fact that synovial lesions in RA are morphologically and functionally heterogeneous with B cells participating in either GC reactions, GC-negative $\mathrm{T}$ cell-B cell aggregates, or unorganized, diffuse lymphocytic infiltrates. BLyS was found in all tissues and derived from macrophages. APRIL was produced by CD83 ${ }^{+}$ DCs and was highest in GC-containing tissues. The APRIL/BLyS receptor TACI was expressed on plasma cells, B cells, and T cells. However, $\mathrm{TACI}^{+} \mathrm{T}$ cells were restricted to aggregate and diffuse synovitis and were absent in $\mathrm{GC}^{+}$synovitis. In vivo blocking of APRIL/BLyS with TACI:Fc essentially abrogated $\mathrm{GC}^{+}$synovitis, suggesting a critical role of the TNF homologs in the formation and maintenance of ectopic GCs. Conversely, treatment with TACI:Fc enhanced $\mathrm{T}$ cell function without affecting Ig production in synovial lesions that contained $\mathrm{TACI}^{+} \mathrm{T}$ cells, suggesting that APRIL and BLyS have immunostimulatory as well as immunosuppressive function in RA.

\section{Results}

APRIL and BLyS production in rheumatoid synovitis. To determine the role of the TNF ligands APRIL and BLyS in rheumatoid synovitis, we analyzed a cohort of 72 synovial biopsies for the tissue expression of both cytokines. Synovial tissues were classified into 3 categories according to the type of lymphoid microstructure. Sixteen tissues had GC reactions, 30 tissues exhibited GC-negative $\mathrm{T}$ cell-B cell aggregates, and 26 tissues showed diffuse synovitis. Representative histologies are shown in Figure 1A. As previously described (4), tissues with GC reactions expressed high levels of LT- $\beta$ mRNA, whereas this TNF homolog was present at low concentrations in aggregate and diffuse synovitis $(P<0.001)$ (Figure 1B). Tissues with ectopic GCs contained the highest numbers of DCs, mostly in the T cell zones surrounding the GCs. In contrast, diffusely organized infiltrates included low numbers of DCs (data not shown). Accordingly, mRNA tissue expression of the chemokine CCL19 was found at highest concentrations 
in $\mathrm{GC}^{+}$samples $(P=0.008$ versus aggregate; $P<0.001$ versus diffuse) (Figure 1B). Aggregate synovitis contained intermediate levels of CCL19-specific sequences, and diffuse synovitis produced lower levels. To examine whether the synovitis type impacted $B$ cell/plasma cell function, we quantified $\operatorname{IgG}_{1 / 2}$-specific sequences in the cohort of 72 tissue extracts. The highest levels of $\operatorname{IgG}_{1 / 2}$ transcripts were found in tissues with GC reactions. Aggregatecontaining tissues produced significantly lower concentrations $(P<0.04)$, and $\operatorname{IgG}_{1 / 2}$ transcripts were 100 -fold lower in tissue samples with diffuse infiltrates $(P<0.001)$.

Tissue expression of APRIL mRNA was closely correlated with the production of the DC-derived chemokine CCL19 (Figure 1C). The median concentration of APRIL-specific transcripts in $\mathrm{GC}^{+}$ synovitis was 9,669 copies and was significantly higher $(P<0.001)$ than that in aggregate synovitis (2,967 copies). In tissue sections with diffuse synovitis, APRIL mRNA concentrations were more than 10 -fold lower, with a median of 882 copies $(P<0.001)$. A different picture emerged for BLyS mRNA which was abundantly detected at indistinguishable levels in all types of synovitis. These findings suggest that APRIL, rather than BLyS, mRNA levels correlate with the variability of tissue $B$ cell function.

To identify the APRIL- and BLyS-producing cells in synovitis, we utilized 2-color immunohistochemistry of frozen tissue sections. Cells staining positive for APRIL were localized the outskirts of B cell follicles, typically in the T cell zones. Double immunofluorescence demonstrated that APRIL-producing cells expressed CD83, a marker for activated DCs (37) (Figure 2A). In all tissues, the overlap between $\mathrm{CD} 3^{+}$and $\mathrm{APRIL}^{+}$cells was complete. BLyS-specific antibodies reacted with a subset of large cells distributed throughout the tissue infiltrates. Double labeling using the macrophage marker CD68 and BLyS confirmed that BLySproducing cells were tissue macrophages (Figure $2 \mathrm{~B}$ ). $\mathrm{CD} 83^{+} \mathrm{DCs}$ were negative for BLyS protein.

APRIL/BLyS receptors in rheumatoid synovitis. The biologic effects of APRIL and BLyS in rheumatoid synovitis should be dependent on which cell types express the relevant receptors. To assess receptor expression in synovitis, the 72 tissue samples were analyzed for the representation of BAFF-R, BCMA, and TACI-specific sequences by real-time PCR. Transcripts for all 3 receptors were detected in all tissue biopsies (Figure 3). Expressions of BAFF-R and TACI were independent from the synovitis type. Overall, transcripts for BAFF-R were more abundant than those for TACI, but no correlation emerged between the lymphoid microstructure and expressions of these 2 receptors. Conversely, BMCA mRNA was expressed differently, with the highest levels in tissues with organized $T$ cell and $\mathrm{B}$ cell clusters. $\mathrm{GC}^{+}$synovitis and aggregate synovitis both contained significantly higher concentrations of BMCA-specific transcripts than did diffuse synovitis $(P<0.001$ and $P=0.006$ com-

\section{Figure 2}

Cellular origin of APRIL and BLyS in rheumatoid synovitis. Frozen tissue sections were double stained with either anti-APRIL and antiCD83 or anti-BLyS and anti-CD68. (A) APRIL was visualized with VectorBlue, and CD83 was detected with VectorRed. APRIL was exclusively produced by activated DCs localized in the T cell zones. (B) Binding of anti-BLyS was developed with 3,3'-diaminobenzidine tetrahydrochloride (brown staining), and CD68 expression was demonstrated with VectorRed. BLyS derived exclusively from $\mathrm{CD}^{+} 8^{+}$macrophages. Immunohistochemistries shown are representative of 20 experiments. Original magnification, $\times 600$ (right panels in B). Scale bars: $200 \mu \mathrm{m}$ (A); $50 \mu \mathrm{m}$ (B). pared with diffuse synovitis). Quantities of BCMA mRNA were not significantly different in synovial lesions with GC reactions versus aggregate formations $(P<0.1)$.

TACI $^{+}$T cells in RA tissue lesions. Whereas BCMA is mostly expressed on B cells, TACI also regulates T cell function (28). Also, $\mathrm{TACI}^{-/-}$ mice develop a fatal lymphoproliferative syndrome, suggesting that APRIL and BLyS have immunoregulatory effects beyond supporting B cell differentiation and antibody production. To explore whether APRIL and BLyS have multiple distinct functions in rheumatoid synovitis, we set out to identify $\mathrm{TACI}^{+} \mathrm{T}$ cells in the tissue lesions. In all types of rheumatoid synovitis, $\mathrm{TACI}^{+}$cells were represented in the synovial infiltrates, but the composition of the TACI-expressing population was distinct in $\mathrm{GC}^{+}$synovitis compared with aggregate and diffuse synovitis. In tissues with typical GC reactions, $\mathrm{TACI}^{+}$cells were found outside of the follicles and accumulated in 2 distinct areas. They were either lined up in the sublining stroma below the layers of hyperplasic synoviocytes or localized in the interfollicular regions. Dual-color immunohistochemistry of frozen tissue sections demonstrated that these TACI-expressing cells were negative for CD3. A subset of the $\mathrm{TACI}^{+}$cells in the interfollicular areas stained positive for $\mathrm{CD} 20$. The majority of TACI ${ }^{+}$cells in $\mathrm{GC}^{+}$synovitis were identified as plasma cells based on characteristic cellular morphology and expressions of CD138 and VS38c (Figure 4C).

In aggregate synovitis, TACI-expressing cells were localized in the $T$ cell-B cell clusters; in diffuse synovitis, they were distributed throughout the infiltrates (Figure 4A). Double staining with antiCD3, anti-CD20, and anti-CD138 revealed that T cells, B cells, and plasma cells contributed equally to the $\mathrm{TACI}^{+}$population. All diffuse and aggregate synovitis tissue sections examined had CD3 T cells expressing the TACI receptor (Figure 4B). Thus, the representation of $\mathrm{TACI}^{+} \mathrm{T}$ cells in rheumatoid lesions correlated closely with the type of lymphoid organization and was typical for synovitis variants with $\mathrm{T}$ cell-B cell aggregates and unorganized infiltrates.

To confirm the presence of $\mathrm{TACI}^{+} \mathrm{T}$ cells in diffuse and aggregate synovitis and to estimate the frequencies of such $\mathrm{T}$ cells in the tissue lesions, we proceeded with multicolor flow cytometric anal-

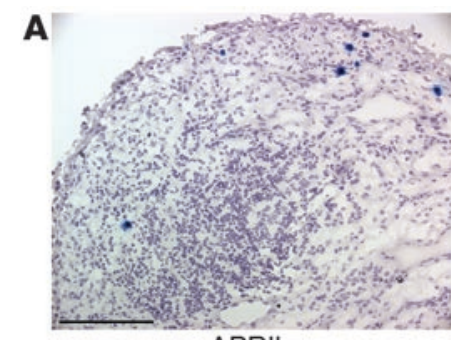

APRIL

B

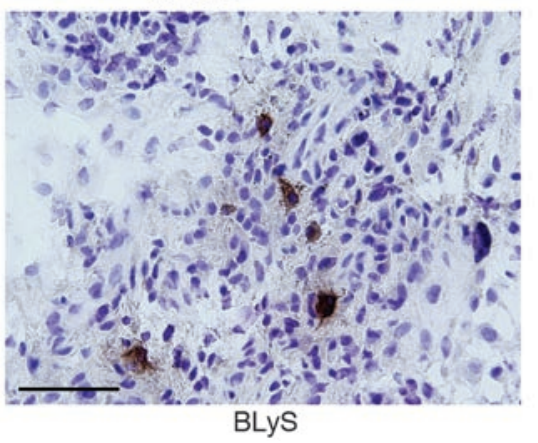
BLyS

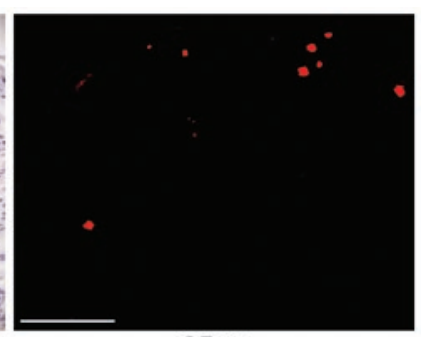

CD83

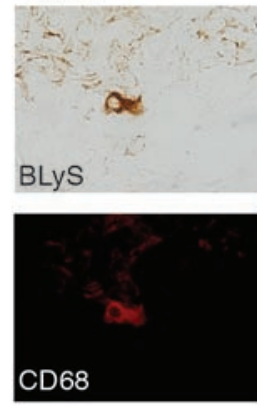

CD68 


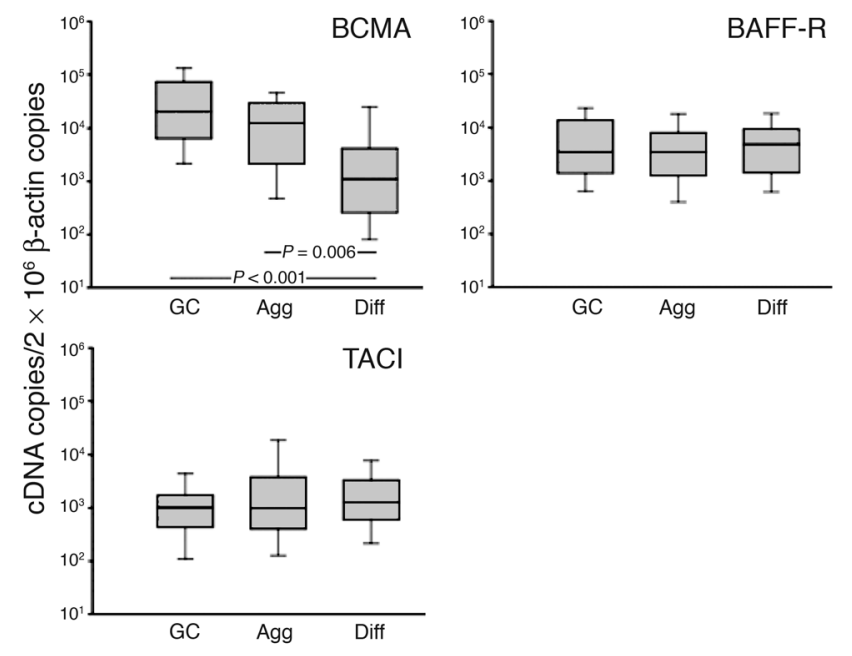

ysis of cells isolated freshly from tissue biopsies. Synovial tissue samples from 3 patients with aggregate synovitis and 3 patients with diffuse synovitis were digested, and lymphocytes were isolated by density gradient and stained with anti-TACI combined with either anti-CD3, anti-CD20, or anti-CD138. Almost all CD138+ plasma cells were positive for TACI. A subset of about $6-10 \%$ of tissue-derived $\mathrm{CD}^{+} \mathrm{T}$ cells expressing TACI on the surface was found regardless of whether the tissues had aggregates or diffuse infiltrates. Representative results obtained from a tissue with classical aggregate synovitis are shown in Figure 5. CD20+ $\mathrm{B}$ cells that reacted with anti-TACI antibodies were consistently found, but their frequency varied from patient to patient.

Blockade of APRIL/BLyS in synovitis with GC formation. The production of APRIL and BLyS in all types of rheumatoid synovitis and the presence of tissue-infiltrating $\mathrm{TACI}^{+} \mathrm{T}$ cells in selected variants of the rheumatoid lesions provided an experimental system to test the in vivo functions of the 2 TNF homologs in RA. We generated human synovium-SCID mouse chimeras by implanting pieces of synovial tissues collected from patients with active disease into NOD-SCID mice. In this model, full engraftment of the human tissue is reached after 6-7 days. On days 6, 9, and 12,

\section{Figure 4}

Topography and phenotype of TACl-expressing cells in rheumatoid synovitis. (A) Sections of synovial tissues with $\mathrm{GC}^{+}$(left), aggregate (middle), and diffuse (right) synovitis were stained with anti-TACI Abs. $\mathrm{CD}^{+} \mathrm{T}$ cells and CD20+ $\mathrm{B}$ cells forming the $\mathrm{GC}$ are marked in the insets. TACl-expressing cells (brown staining) in $\mathrm{GC}^{+}$synovitis were positioned in the interfollicular areas (left). $\mathrm{TACl}^{+}$cells in aggregate tissues mapped preferentially to the lymphoid clusters (middle). In diffuse synovitis, $\mathrm{TACl}^{+}$cells were dispersed throughout the tissue (right). (B) In $\mathrm{GC}^{+}$synovitis, $\mathrm{TACl}^{+}$cells (brown staining) were negative for the CD3 marker (blue staining). In contrast, tissues with aggregate (middle) and diffuse synovitis (right) contained $\mathrm{TACl}^{+}$cells (blue staining) that expressed CD3 (brown staining). The insets show higher magnifications of representative $\mathrm{TACl}^{+}$cells. DAB, 3,3'-diaminobenzidine tetrahydrochloride; VB, VectorBlue. (C) The TACI receptor (blue staining) was intensively expressed on a subset of $\mathrm{CD} 138^{+} / \mathrm{VS} 38 \mathrm{c}^{+}$plasma cells (brown staining). Immunohistochemistries shown are representative of 15 experiments. Original magnification, $\times 600$ (insets in B and C). Scale bars: $200 \mu \mathrm{m}$.

\section{Figure 3}

Expression of APRIL and BLyS receptors in rheumatoid synovitis. Tissue samples $(n=72)$ were stratified according to synovitis pattern. cDNAs from tissue extracts were normalized for the concentration of $\beta$-actin copies, and BCMA, BAFF-R, and TACI transcripts were analyzed by real-time $P C R$. All 3 receptors were detected in all tissue samples. Quantities of BAFF-R and TACI transcripts were similar in all 3 types of synovitis. BCMA was produced at low abundance in tissues with diffuse synovitis and in significantly higher amounts in aggregate $(P=0.006)$ and $\mathrm{GC}^{+}$synovitis $(P<0.001)$. Results are given as box plots as described in Figure 1.

the synovium-SCID chimeras were injected with $200 \mu \mathrm{g}$ of the soluble decoy receptor TACI:Fc. Control animals received human Fc protein lacking TACI.

Treatment with soluble TACI had profound effects in tissues with ectopic GC formation. TACI:Fc efficiently inhibited $\operatorname{IgG}_{1 / 2}$ production about 13 -fold $(P<0.001)$ and decreased tissue production of IFN- $\gamma$ by almost 4-fold $(P<0.05)$ (Figure 6$)$.

To explore how blockade of APRIL and BLyS affected the architecture of synovial follicles, we collected the synovial grafts 2 weeks after TACI:Fc injections and stained tissue sections for the T cell marker CD3 and B cell marker CD20. Treatment with TACI: Fc resulted in the destruction of ectopic GCs, combined with a marked reduction of $\mathrm{CD} 20^{+} \mathrm{B}$ cells and $\mathrm{CD}^{+} \mathrm{T}$ cells (Figure 7). $B$ cells almost disappeared from the lesions, and $T$ cell densities declined to less than half of the control densities (Figure 7B). To analyze whether the collapse of ectopic GCs was associated with the loss of FDC, cDNAs from the synovial tissues were assayed for the presence of CD21 long isoform (CD21L) transcripts, a marker exclusively expressed by FDCs (38). TACI:Fc treatment tended to abrogate $\mathrm{CD} 21 \mathrm{~L}$ transcription, confirming that FDC networks were no longer maintained (Figure $7 \mathrm{C}$ ). These findings linked APRIL and BLyS to the process of lymphoid organogenesis with roles in GC formation and regulatory function for B cells and $\mathrm{T}$ cells in the rheumatoid lesion.

Blockade of APRIL/BLYS in aggregate and diffuse synovitis. Both aggregate and diffuse synovitis were characterized by the inclusion of TACI+ ${ }^{+}$cells in the infiltrates. We examined the effects of APRIL and BLyS blockade in tissues from 5 patients with $\mathrm{GC}^{-} \mathrm{T}$
A

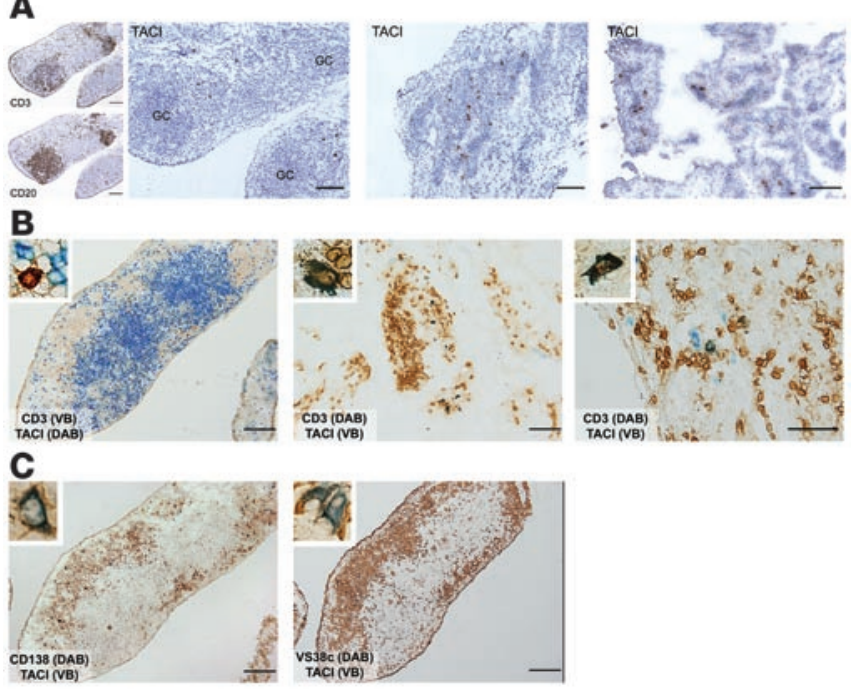



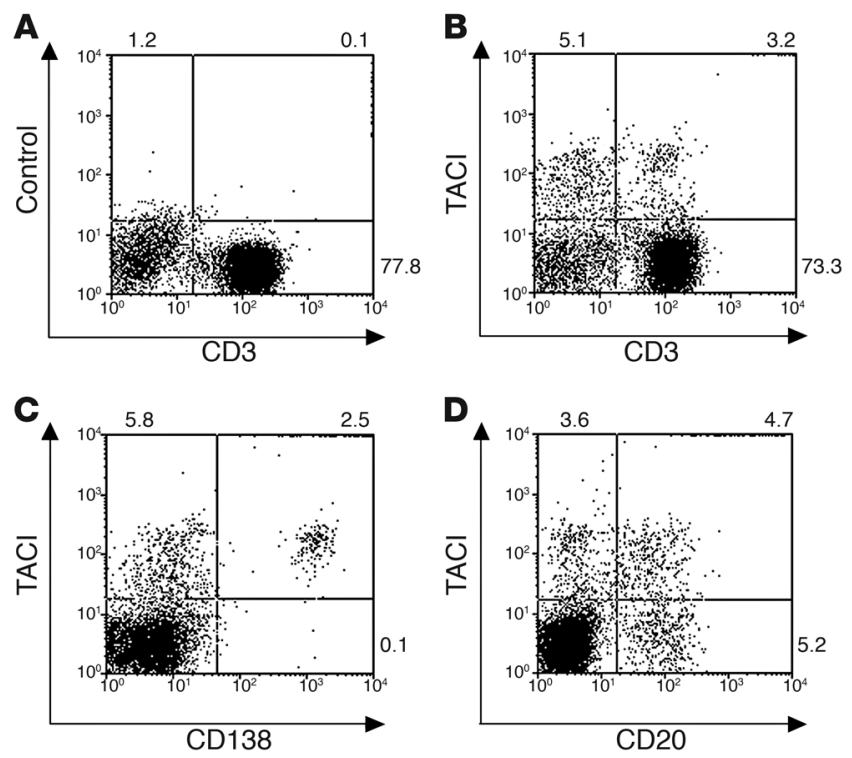

cell-B cell clusters and in 5 patients with diffuse synovitis. The biologic consequences of inhibiting APRIL and BLyS in these synovitis variants were clearly distinct from the outcome in $\mathrm{GC}^{+}$ synovitis (Figures 8 and 9). Injection of TACI:Fc had essentially no effects on the transcription of Ig. In both aggregate and diffuse synovitis, transcription of IgG continued despite the disruption of APRIL and BLyS function. Instead, regulation of T cell activity was the primary target of the TNF homologs. In aggregate-containing synovial grafts from TACI:Fc-treated chimeras, mRNA levels of the T lymphocyte activation marker IFN- $\gamma$ were markedly increased $(P<0.001)$, and upregulation of IFN- $\gamma$ mRNA levels increased by approximately 6 -fold $(P<0.001)$ in cases with diffuse synovitis. The quantification of the proinflammatory cytokine TNF- $\alpha$ revealed a significant reduction $(P<0.02)$ in aggregate synovitis and unchanged levels in tissues with diffuse infiltrates $(P=0.4)$ (Figures 8 and 9).

\section{Discussion}

Ligands of the TNF superfamily are known to critically regulate immune responses and immune-mediated tissue injury. BLyS is now considered to be one of the major factors regulating the size and repertoire of the B cell compartment (39) and thus emerges as a potential driver of B cell hyperplasia and autoantibody production in human autoimmune disease. The contribution of APRIL in B cell autoimmunity is less well understood (40), but both of these TNF homologs have been implicated in breaking tolerance and mediating autoimmunity in mice $(18,19,41)$. The data presented here demonstrate that APRIL and BLyS have positive as well as negative regulatory effects in RA, a disease in which B cells appear to play an indispensable role. Absorption of APRIL and BLyS through treatment with the TACI:Fc fusion protein had deleterious effects on the structural and functional integrity of synovial GCs, thereby assigning a role for APRIL and BLyS in the process of inflammation-associated lympho-organogenesis. A complex picture of treatment-related effects was found in tissues that lacked ectopic GCs and possessed TACI ${ }^{+} \mathrm{T}$ cells. Here, preventing APRIL and BLyS signaling through soluble TACI receptors led to increased tissue production of the proinflammatory cytokine IFN- $\gamma$.

\section{Figure 5}

$\mathrm{TACl}^{+} \mathrm{T}$ cells in aggregate synovitis. Four-color flow cytometry analysis was used to phenotype $\mathrm{TACl}^{+}$cell populations in synovial infiltrates from patients with aggregate synovitis. Tissue-infiltrating cells were isolated from freshly harvested synovial biopsies and stained with PerCP-labeled anti-CD3 and APC-labeled anti-CD138. (A) Control stain with $\mathrm{PE}$-labeled, isotype-matched $\mathrm{Ab}$ on $\mathrm{CD}^{+} \mathrm{T}$ cells. (B) $\mathrm{TACl}$ is expressed on a subset of synovial $C D 3^{+} T$ cells. (C) Expression of TACI by synovial CD138+ plasma cells. (D) A subset of CD20+ $B$ cells is positive for TACl. Results are representative of 3 tissues with aggregate and 3 tissues with diffuse synovitis. Percentage of cells in each quandrant is indicated.

Thus, BLyS and APRIL regulate synovial inflammation in RA, with negative signals being mediated through $\mathrm{TACI}^{+} \mathrm{T}$ cells. $\mathrm{TACI}^{+} \mathrm{T}$ cells could possibly be developed into a new therapeutic strategy aimed at downregulating rheumatoid synovitis.

Soon after the discovery of BLyS, it became clear that this pivotal survival factor for B cells derived from myeloid cells such as monocytes, macrophages, and DCs (15). This finding assigned primary control of the B cell compartment size and repertoire to professional APCs. However, recent data suggest that the expression of the relevant receptors on $\mathrm{B}$ cells may be regulated through signals mediated by the $\mathrm{B}$ cell receptor, thereby implicating antigenic stimulation in this critical aspect of the immune system (42).

The rule that BLyS is produced by myeloid cells was maintained in rheumatoid synovitis. BLyS transcription was highly abundant; however, only a subpopulation of $\mathrm{CD} 68^{+}$macrophages had the capability to produce BLyS protein, and $\mathrm{CD}^{+} 3^{+} \mathrm{DCs}$ were negative. We did not find any distinguishing characteristic features for BLyS-producing macrophages. Their morphology was that of typical tissue macrophages; they did not resemble synoviocytes. Their location in the tissue appeared random, and all distinct types of synovitis had BLyS $\mathrm{S}^{+}$macrophages. In this context, it is important to note that synovitis is characterized by the lack of tissue-residing neutrophils, a cell population recently described as being an important producer of BLyS (14). In contrast, neutrophils are often abundantly found in synovial fluid and are possibly the source for the elevated BLyS levels found in the synovial fluid of RA patients (21). It is doubtful that BLyS released in the synovial space would have a major impact on the function of cells deeply embedded in the hyperplastic synovial membrane. BLySmediated functions in the synovial infiltrates are likely controlled through macrophage-derived proteins.

A similar selective picture emerged for the cellular origin of APRIL. The protein was exclusively detected in $\mathrm{CD}^{+} 3^{+} \mathrm{DCs}$. Biologic active heterotrimers of APRIL and BLyS have been previously described (27); however, since these cytokines are supplied from different cellular sources, this mechanism is unlikely to have relevance in synovitis. The density of DCs in synovitis is highest in tissues with ectopic GCs, and DCs in the T cell zones of such GCs were typically positive for APRIL. The profound effects that TACI:Fc had in dismantling such highly organized GCs raises the possibility that DCs, through the release of APRIL, influence lymphoid organogenesis.

The current study identified 2 distinct biologic effects of APRIL and BLyS in RA. Aberrant GCs ceased to exist, B cells and T cells effluxed from the lesions, and Ig production decreased when APRIL and BLyS were blocked with TACI:Fc. BLyS has been implicated in regulating GC function (43). This effect is likely mediated through 

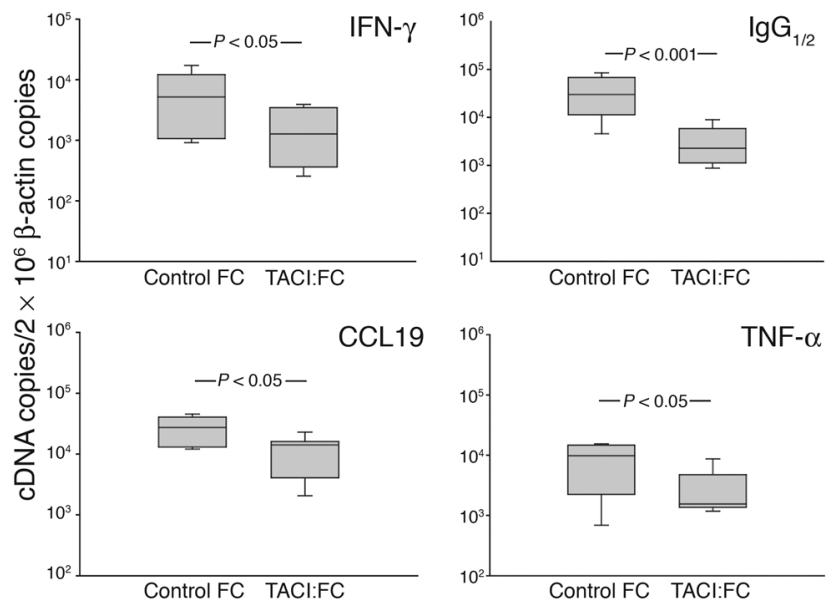

the BLyS receptor, BCMA, which is preferentially expressed on follicular B cells. We did not see expression of TACI on any cell type directly associated with GCs. The essential role of APRIL/BLyS for $\mathrm{GC}$ function is well in line with previous reports. The high sensitivity of IgG transcriptions to TACI:Fc treatment may relate to a high frequency of short-lived plasma cells that are highly dependent on a functional GC. It is less likely that TACI:Fc has a direct effect on plasma cell function. The inhibitory action of TACI:Fc on T cell and macrophage function could result from impaired antigen presentation and T cell triggering. Previous adoptive transfer experiments of tissue-derived T cells into SCID chimeras have shown that the functional activity of such $T$ cells depends strictly on B cells, which suggests that B cells in rheumatoid synovitis serve as critical APCs.

The more surprising outcome of the current study relates to the finding that in the majority of rheumatoid synovitis cases, TACI:Fc did not block - but rather enhanced - inflammatory activity. In tissues that did not possess ectopic GCs, such as in aggregate and diffuse synovitis, absorbance of APRIL and BLyS led to enhanced IFN- $\gamma$ production. We have recently described that GC-rich tissues produced significantly more IFN- $\gamma$ (44). BLyS or APRIL may be central to this difference because the inhibition of IFN- $\gamma$ by TACI: Fc in GC tissues and the enhancement in diffuse tissues essentially equalized this difference between the tissues. Transcription of Ig was unaffected, consistent with the model that the function of long-lived plasma cells is not dependent on BLyS or APRIL.

BLyS receptor transcripts were present in similar concentrations in all tissue types. BCMA mRNA was low in aggregate and diffuse synovitis. TACI was detected on 3 cell types: $T$ cells, a population

\section{Figure 7}

APRIL/BLyS blockade results in collapse of ectopic GCs. GC+ synovium was implanted into SCID mice, and the chimeras were treated with TACl:Fc or control Fc as described in Figure 6. Explanted synovial grafts were embedded, and frozen tissue sections were stained for CD3 and CD20. Tissue extracts were assayed by PCR for the presence of CD21L transcripts, a marker for FDCs exclusively expressed in synovitis with intact GCs. (A) Treatment of GC+ synovitis with TACl: Fc resulted in the destruction of ectopic GCs. Scale bars: $50 \mu \mathrm{m}$. (B) In synovial grafts treated with $\mathrm{TACl}: \mathrm{Fc}$, few $\mathrm{CD} 20^{+} \mathrm{B}$ cells remained, and $\mathrm{CD}^{+} \mathrm{T}$ cells were markedly reduced. HPF, high-powered field. (C) TACI:Fc injection caused loss of CD21L, confirming that FDC networks were no longer sustained. First lane, size markers. +, positive control; -, negative control.

\section{Figure 6}

Neutralization of APRIL/BLyS in vivo with TACI:Fc in $\mathrm{GC}^{+}$synovitis. Human synovium-SCID mouse chimeras were generated with GCcontaining synovial tissues from RA patients. On days 6, 9, and 12 after implantation, chimeras were injected i.p. with TACl:Fc or control Fc $(200 \mu \mathrm{g} / \mathrm{d})$. On day 14 , synovial grafts were explanted; cDNAs were adjusted for the concentration of $\beta$-actin transcripts. Cytokinespecific sequences were quantified by real-time PCR. Results from 6 treated and 6 control mice are given as box plots, as described in Figure 1. Blockade of APRIL and BLyS with soluble TACI:Fc resulted in marked inhibition of $\operatorname{lgG}_{1 / 2}$ transcription and reduction of IFN- $\gamma, T N F-\alpha$, and CCL19 mRNA.

of B cells, and a majority of plasma cells. Expression of TACI on plasma cells has thus far not been reported. In the mouse, plasma cells do not appear to express TACI (45). Only a small fraction of human B cells express TACI when they differentiate into CD38+ plasmablasts in vitro. TACI expression on synovial plasma cells was consistently seen by immunohistochemistry as well as flow cytometry. It remains to be seen whether this applies to plasma cells in general or only to plasma cells in inflammatory infiltrates. The fact that only tissues that contained $\mathrm{TACI}^{+} \mathrm{T}$ cells responded with upregulation of IFN- $\gamma$ production implicated that population as the premier target for APRIL and BLyS in the lesions. The lacking effects of TACI:Fc on Ig production and the enhancement of $T$ cell function suggest that the inhibitory signals mediated by APRIL/BLyS are dominant.

Whereas BCMAs display specificity for B cells, BAFF-R and TACI can also be expressed by $\mathrm{T}$ cells $(32,45)$. In circulating $\mathrm{T}$ cells, TACI is infrequently seen, and polyclonal stimulation is necessary to bring the receptor to the surface of some $\mathrm{T}$ cells. $\mathrm{TACI}^{+} \mathrm{T}$ cells in the tissue lesions had a preference for the $\mathrm{T}$ cell-B cell aggregates and were distinctly absent in those tissues that had formed organized GCs.

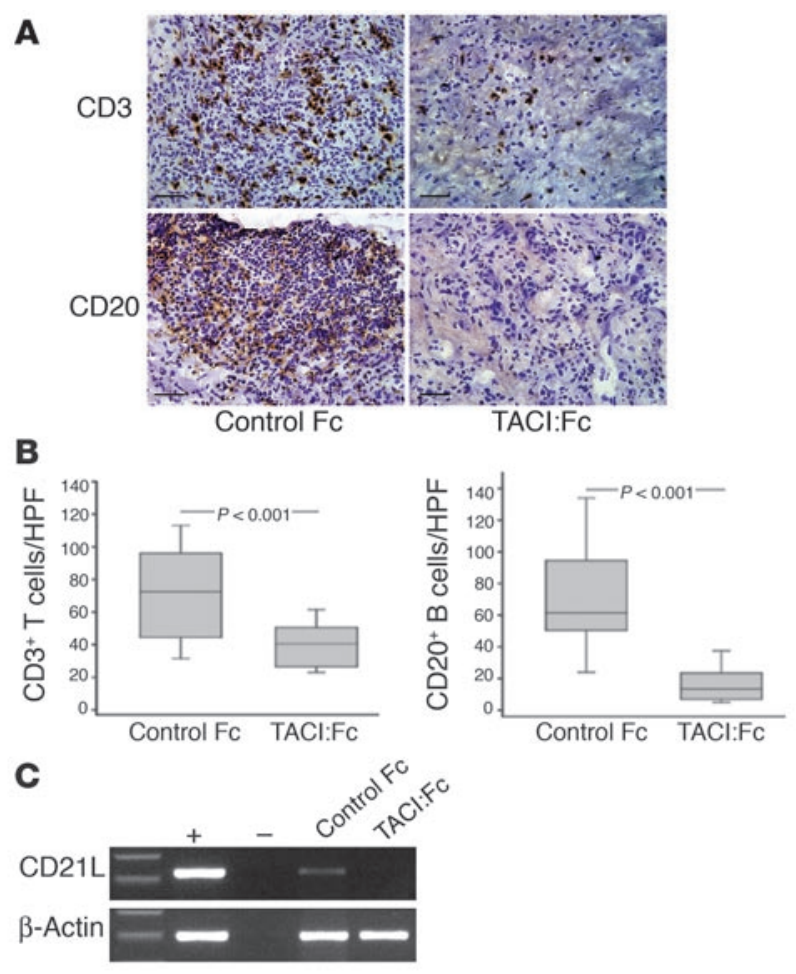



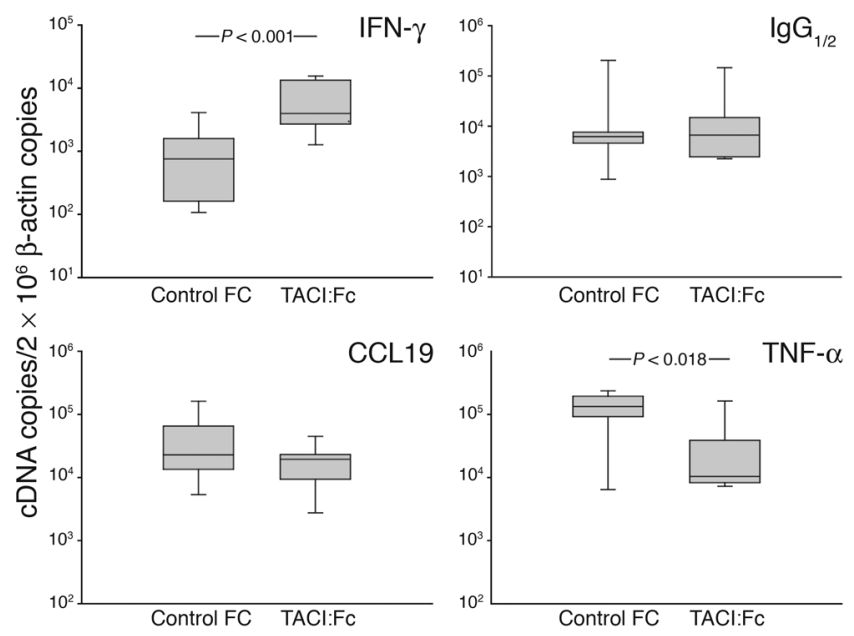

Figure 8

Therapeutic effects of TACl:Fc in aggregate synovitis. Human synovium-SCID mouse chimeras implanted with synovial tissues with aggregates were treated with TACl:Fc or control Fc and then analyzed as described in Figure 6. Results from experiments with tissues from 5 patients are shown. Blocking APRIL/BLyS left production of $\lg G_{1 / 2}$ transcripts totally unaffected. Following treatment with $\mathrm{TACl}: \mathrm{FC}, \mathrm{IFN}-\gamma$ production markedly increased. DC function assessed through CCL19 remained unchanged. Transcription of TNF- $\alpha$ was significantly diminished. Results are given as box plots, as described in Figure 1.

It has been proposed that APRIL and BLyS may have costimulatory activity for T cells (46), quite opposite to the in vivo effects seen here. In mice, the depletion of TACI has been associated with massive abnormalities in the B cell compartment, including hyperplastic B cells infiltrating diffusely in organs, lymphoma development, autoantibody production, and glomerulonephritis. These studies have identified TACI as a negative receptor. Whether the primary target of such negative signals is T cells or B cells has not yet been explored in mice. The current study suggests that APRIL/BLyS suppress the production of IFN- $\gamma$ in aggregate and diffuse synovitis, probably representing an only partially successful attempt to downregulate tissue inflammation. The question remains open as to whether demasking this inhibitory function of APRIL/BLyS through blocking these 2 mediators could result in unwanted immunostimulatory consequences in patients with the appropriate type of synovitis. Follow-up studies in patients undergoing subsequent synovial biopsies have shown that the patterning of synovitis is stable over time and applies to all affected joints in the body. For patients in whom the downregulatory functions of APRIL and BLyS dominate over their role in sustaining B cells and their organization in the synovium, substitution for both mediators may be more therapeutically beneficial than blockade. Considering that APRIL-producing DCs are only present in very low frequencies in aggregate and diffuse synovitis, BLyS emerges as the likely mediator through which this regulatory effect on IFN- $\gamma$ production is transmitted.

TNF- $\alpha$ derives from several different cell types in synovitis. Besides macrophages, $T$ cells can be a major source of this cytokine. Under most conditions, tissue TNF- $\alpha$ production correlates closely with IFN- $\gamma$ production. However, in aggregate synovitis, TACI:Fc treatment increased IFN- $\gamma$ but reduced TNF- $\alpha$. One possible explanation is that TNF- $\alpha$ derives from different sets of producer cells in this synovitis type, such that APRIL or BLyS contributed to TNF- $\alpha$ induction while suppressing IFN- $\gamma$ through targeting $\mathrm{TACI}^{+} \mathrm{T}$ cells.

Results presented here extend the role of the TNF homologs BLyS and APRIL in human autoimmune disease. BLyS serum levels are significantly increased in patients with RA (21), SLE (47), or SS (22). A recent report found elevated serum levels of APRIL in SLE patients compared with normal controls and patients with RA (48). A contributory role of BLyS and APRIL in promoting B cell survival, hyperplasia, and autoantibody production can be easily imagined. To conceptualize on this model, clinical trials aimed at disrupting BLyS activity in patients with SLE and RA have been started. Data on clinical efficacy have not yet been published, but preliminary results suggest that autoantibody levels are only partially affected. Based on the results of blocking APRIL and BLyS in RA tissue lesions, we propose that the 2 mediators may have additional pathways through which they interfere with the risk for and the severity of autoimmune disease. By triggering $\mathrm{TACI}^{+} \mathrm{T}$ cells, APRIL/BLyS seem to provide a negative signal, suppressing production of the key T cell cytokine IFN- $\gamma$. The suspicious absence of $\mathrm{TACI}^{+} \mathrm{T}$ cells in all cases in which tissue-invading $\mathrm{T}$ cells and $B$ cells organized in GC reactions suggests that $\mathrm{TACI}^{+} \mathrm{T}$ cells may be capable of stopping certain pathways. Specifically, they may disrupt the formation of very stable extralymphoid architectures, which facilitate breakdown of tissue tolerance through optimizing antigen capture, storage, and recognition and generating memory responses. Our study also emphasizes the complexity of B cell function in rheumatoid synovitis. The clinical efficacy of B cell depletion via treatment with anti-CD20 antibodies has identified B cells as excellent targets in immunomodulatory therapy. The difference in therapeutic outcomes when $\mathrm{GC}^{+}$and $\mathrm{GC}^{-}$synovitis was treated with TACI:Fc supports the notion that the regulation of B cell function in RA is complex and will require choosing therapeutic targets and interventions that are individualized for each patient.
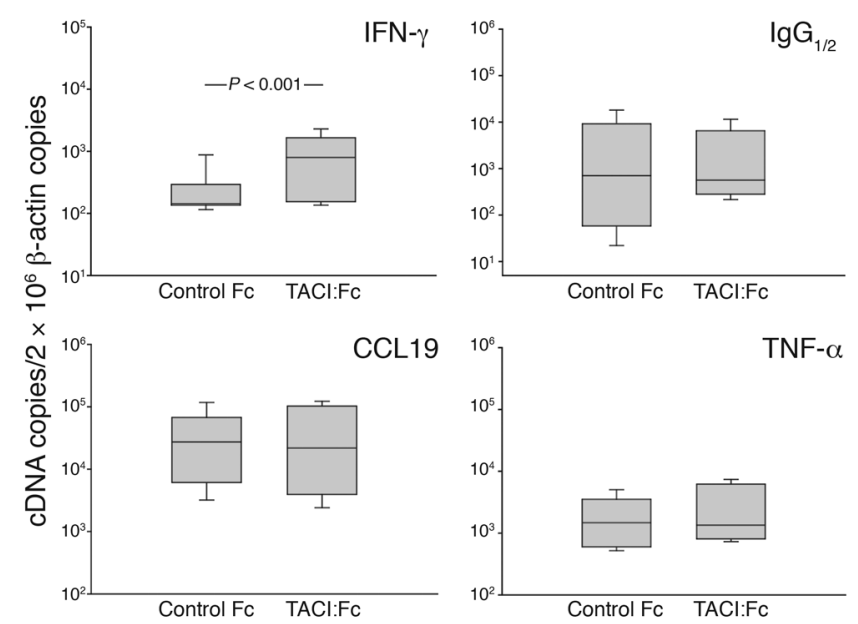

\section{Figure 9}

Treatment with TACl:Fc increases T cell activation in diffuse synovitis. Synovial tissues from 5 patients with diffuse synovitis were implanted into SCID mice. Chimera mice were treated with TACI:Fc and control Fc, and explanted tissue was analyzed as described in Figure 6. Neutralization of APRIL/BLyS in diffuse synovitis markedly increased IFN- $\gamma$ transcripts, whereas productions of $\operatorname{lgG}_{1 / 2}, C C L 19$, and TNF- $\alpha$ mRNA were unaffected. Results are given as box plots, as described in Figure 1. 
Table 1

Clinical characteristics of the study population

\begin{tabular}{lccc}
\hline & \multicolumn{3}{c}{$\begin{array}{c}\text { Synovitis type } \\
\text { Aggregate }\end{array}$} \\
& Follicular & Diffuse \\
Patients $(n)$ & 16 & 30 & 26 \\
Sex (\% female) & 81 & 83 & 73 \\
$\begin{array}{l}\text { RA duration } \\
\text { (years; mean } \pm \text { SD) }\end{array}$ & $15.8 \pm 9.3$ & $15.0 \pm 8.1$ & $15.3 \pm 11.4$ \\
Age at disease onset & $36.0 \pm 17.7$ & $38.9 \pm 13.6$ & $39.3 \pm 19.4$ \\
$\begin{array}{l}\text { (years; mean } \pm \text { SD) } \\
\text { RF (\% positive) }\end{array}$ & 100 & 84 & 81 \\
No. joint surgeries & $6.1 \pm 3.5$ & $4.2 \pm 3.3$ & $5.2 \pm 3.7$ \\
$\begin{array}{l}\text { Extra-articular disease } \\
\text { Nodules (\%) }\end{array}$ & 47 & & \\
Major organ disease (\%) & 7 & 17 & 32 \\
\hline
\end{tabular}

$\mathrm{RF}$, rheumatoid factor.

\section{Methods}

Study population. Synovial tissue specimens were collected from a cohort of 72 patients with RA who were undergoing synovial biopsy, synovectomy, or total joint replacement surgery. All patients were diagnosed according to the 1987 revised criteria of the American College of Rheumatology, were seropositive for rheumatoid factor, had unequivocal destructive RA, and had active disease at the time of surgery. Most of the patients were on methatrexate as a disease-remitting agent; none of the patients were on anti-TNF antagonists. Demographic data for the study population is given in Table 1. The protocol was approved by the Mayo Clinic Institutional Review Board and the Emory University Institutional Review Board.

Histopathologic evaluations of tissue specimens. Hematoxylin-stained sections of the synovial tissue were analyzed for the cellular organization of inflammatory infiltrates, with particular attention paid to the lymphoid microstructure and the arrangement of T cells, B cells, and macrophages. All analyses of tissue specimens were performed by one hemopathologist (P.J. Kurtin) who was unaware of the clinical course or any laboratory findings. Synovial tissue specimens were grouped according to the following criteria: (a) T cell and B cell follicles with GC formations, (b) T cell and B cell aggregates without GCs, and (c) diffuse tissue infiltration of T cells and B cells with the absence of a distinct lymphoid microstructure. GC formation was confirmed by standard histological criteria (49) and PCR analysis for the CR2/CD21L expressed on FDCs (38). This histological classification has proven useful for us in pathogenetic studies. However, it has not yet been validated in clinical studies. In particular, its importance for clinical outcome and treatment responses is unclear.

Immunohistochemistry. Frozen human synovial tissues embedded in OCT were cut into $5-\mu \mathrm{m}$ sections, fixed in acetone for 10 minutes, air dried, and fixed in $1 \%$ paraformaldehyde/EDTA ( $\mathrm{pH} 7.2$ ) for 3 minutes. Endogenous peroxidase activity was blocked with $0.3 \% \mathrm{H}_{2} \mathrm{O}_{2}$ in $0.1 \%$ sodium azide, and endogenous alkaline phosphatase activity was inhibited by the addition of levamisole (Vector Laboratories). Nonspecific binding was blocked with 5\% normal blocking serum from the appropriate species for 15 minutes. The following primary Abs were used for immunohistochemistry: anti-human CD3 mAb (1:100 dilution), anti-human CD20 mAb (1:100 dilution), antiCD138 mAb, and anti-human plasma cell p63 Ab (all from DakoCytomation); anti-human CD83 mAb (1:400 dilution; Research Diagnostics Inc.); anti-human APRIL Ab (1:400 dilution; Alexis Biochemicals Corp.); anti-human BLyS mAb (1:100 dilution; ALEXIS Biochemicals Corp.); and anti-human TACI mAb (1:5 dilution; R\&D Systems). Primary antibodies were incubated either for 60 minutes at room temperature or overnight at $4{ }^{\circ} \mathrm{C}$. After incubation and washing, secondary species-specific Abs (all at 1:400 dilution; DakoCytomation) were applied for 30 minutes at room temperature followed by detection with either the streptavidin-biotin complex immunoperoxidase (VECTASTAIN Elite ABC Kit; Vector Laboratories) or alkaline phosphatase technique (VECTASTAIN ABC-AP Kit; Vector Laboratories). Then the slides were developed with 3,3'-diaminobenzidine tetrahydrochloride (DAB; DakoCytomation) substrate for 3 minutes or alkaline phosphatase substrate kit III (VectorBlue; Vector Laboratories) for 30 minutes and counterstained with hematoxylin for 10 seconds. For double labeling, the slides were incubated with a second primary $\mathrm{Ab}$ for 1 hour and developed using Vector ABC-AP reagents (Vector Laboratories) and alkaline phosphatase kit I (VectorRed; Vector Laboratories) for digital fluorescent visualization. After the final washes, the slides were mounted in VectaMount permanent mounting medium and examined under a light microscope. Control sections were treated in parallel with nonimmune isotype-matched Ig substituting for the primary antibody.

Flow cytometry of tissue-derived cells. Lymphocyte isolation from synovial tissue has been described previously (50). Fresh synovial tissues were digested with $0.05 \mathrm{M}$ HEPES buffer, $3 \mathrm{mg} / \mathrm{ml}$ type 1 A collagenase, $1 \mathrm{mg} / \mathrm{ml}$ hyaluronidase, and $0.1 \mathrm{mg} / \mathrm{ml}$ type IV deoxyribonuclease I at $37^{\circ} \mathrm{C}$ for $30-45$ minutes. Lymphocytes were isolated by Ficoll-Hypaque centrifugation and stained with PerCP-labeled anti-CD3 mAb, FITC-labeled anti-CD20 $\mathrm{mAb}$, and APC-labeled CD138 mAb (BD). For TACI staining, synovial lymphocytes were incubated with mouse anti-TACI mAb (32); PE-labeled goat anti-mouse IgG was used as secondary Abs. For all staining experiments, control stains with isotype-matched Abs were included. Stained cells were analyzed on a FACSCalibur flow cytometer (BD), and WinMDI was used for analysis (Scripps Research Institute).

\section{Table 2}

Characteristics of PCR primers

\begin{tabular}{|c|c|c|}
\hline Target & Sequence $\left(5^{\prime} \rightarrow 3^{\prime}\right)$ & $\begin{array}{c}\text { Annealing } \\
\text { temperature } \\
\left({ }^{\circ} \mathrm{C}\right)\end{array}$ \\
\hline APRIL & $\begin{array}{l}\text { 5'-AGGGTGGAGGGTCTCAAGGC-3' } \\
\text { 5'-GAAGGGAAGAAGGTTGTTACGC-3' }\end{array}$ & 55 \\
\hline BLyS & $\begin{array}{l}\text { 5'-ACCGCGGGACTGAAAATCT-3' } \\
\text { 5'-CACGCTTATTTCTGCTGTTCTGA-3' }\end{array}$ & 55 \\
\hline$L T-\beta$ & $\begin{array}{l}\text { 5'-TGGGAGACGACGAAGGAACAG-3' } \\
\text { 5'-GCCGACGAGACAGTAGAGGTAATAGA-3' }\end{array}$ & 60 \\
\hline $\lg G_{1 / 2}$ & $\begin{array}{l}\text { 5'-ACTCCGACGGCTCCTTCTTC-3' } \\
\text { 5'-GCTCTTCTGCGTGTAGTGGTTGT-3' }\end{array}$ & 55 \\
\hline BCMA & $\begin{array}{l}\text { 5'-GCAGTTTTCGTGCTAATGTTTT-3' } \\
\text { 5'-TCATCACCAGTCCTGCTCTTTT-3' }\end{array}$ & 55 \\
\hline TACl & $\begin{array}{l}\text { 5'-GTGGACAGCACCCTAAGCAAT-3' } \\
\text { 5'-ACCTTCCCGAGTTGTCTGAATT-3' }\end{array}$ & 55 \\
\hline$B A F F-R$ & $\begin{array}{l}\text { 5'-AGACAAGGACGCCCCAGAGCCC-3' } \\
\text { 5'-GTGGGGTGGTTCCTGGGTCTTC-3' }\end{array}$ & 55 \\
\hline$I F N-\gamma$ & $\begin{array}{l}\text { 5'-ACCTTAAGAAATATTTTAATGC-3' } \\
\text { 5'-ACCGAATAATTAGTCAGCTT-3' }\end{array}$ & 55 \\
\hline$T N F-\alpha$ & $\begin{array}{l}\text { 5'-CTTTGGGATCATTGCCCTGTG-3' } \\
\text { 5'-CGAAGTGGTGGTCTTGTTGCT-3' }\end{array}$ & 60 \\
\hline CCL19 & $\begin{array}{l}\text { 5'-CACCAATGATGCTGAAGACTGC-3' } \\
\text { 5'-CGGCGCTTCATCTTGGC-3' }\end{array}$ & 60 \\
\hline CD21L & $\begin{array}{l}\text { 5'-GTGGATTTACTTTGAAGGGCA-3' } \\
\text { 5'-GGCATGTTTCTTCACACCG-3' }\end{array}$ & 55 \\
\hline$\beta$-Actin & $\begin{array}{l}\text { 5'-ATGGCCACGGCTGCTTCCAGC-3' } \\
\text { 5'-CATGGTGGTGCCGCCAGACAG-3' }\end{array}$ & 55 \\
\hline
\end{tabular}


PCR analysis of tissue transcripts. Total RNA was extracted from synovial tissue specimens using TRIzol reagent (Invitrogen Corp.), and cDNA was synthesized. The cDNA was amplified by multiplex real time quantitative PCR (Mx4000; Stratagene) in the presence of SYBR green dye under nonsaturating conditions with cytokine-specific primers. Primer sequences of analyzed cytokines are shown in Table 2. PCR reactions were validated using genespecific sequences with known copy numbers. Amplification cycles included denaturation at $95^{\circ} \mathrm{C}$ for 30 seconds, annealing at primer-specific temperature for 1 minute, and polymerization at $72^{\circ} \mathrm{C}$ for 1 minute, with 5 minutes' initial denaturation at $96^{\circ} \mathrm{C}$ and a final 1 -minute extension at $95^{\circ} \mathrm{C}$. Serial dilutions of known amounts of gene-specific sequences were amplified in parallel. The number of cytokine-specific sequences was determined by interpolation on a standard curve and expressed as the number of cytokine transcripts per $2 \times 10^{6}$ copies of $\beta$-actin to adjust for equal amounts of cDNA.

Treatment of buman synovium-SCID mouse chimeras with TACI:Fc mAbs. NOD. CB17-Prkdssid/J mice were used at the ages of 6-9 weeks (Jackson Laboratory). The protocol was approved by the Animal Care and Use Committee of the Mayo Clinic. For tissue implantation, the mice were anesthetized with i.p. $50 \mathrm{mg} / \mathrm{kg}$ pentobarbital (Abbott Laboratories) and methoxyflurane (Medical Developments International Ltd.) inhalation. Pieces of human synovial tissue with inflammatory infiltrates (approximately $50 \mathrm{~mm}^{3}$ ) were placed in a subcutaneous pocket on the upper dorsal midline. As previously reported, complete tissue engraftment occurred within 1 week (4). Treatment with a recombinant human TACI:Fc fusion protein was initiated on day 6 after tissue implantation. Human synovium-SCID mouse chimeras were injected i.p. with either a single $200-\mu \mathrm{g}$ dose of TACI:Fc or $200 \mu \mathrm{g}$ of Ig:Fc on days 6,9 , and 12 . Fourteen days after implantation, the mice were sacrificed, and the synovial tissue graft was harvested and either embedded in OCT compound (Tissue-Tek; Sakura Finetek Co.) for immunohistochemical analysis or shock frozen in liquid nitrogen $\left(-160^{\circ} \mathrm{C}\right)$ for RNA extraction and cytokine transcript analysis.

Statistics. Analyses, plotting, and data graphing were performed using SigmaStat version 3.0 and SigmaPlot version 8.0 software (SPSS Inc.). Experimental groups were compared by nonparametric Mann-Whitney rank sum tests. $P$ values less than 0.05 were considered to be significant.

\section{Acknowledgments}

This work was funded in part by grants from the NIH (R01 AR 42527, R01 AI 44142, and R01 AR 41974). We thank our colleagues in the Department of Orthopedic Surgery at the Mayo Clinic and at Emory University Hospital for providing us with synovial tissue biopsies. S. Pryshchep gave outstanding support in the preparation of the figures. We appreciate the editorial help of T. Yeargin.

Received for publication April 5, 2005, and accepted in revised form August 23, 2005.

Address correspondence to: Cornelia M. Weyand, Lowance Center for Human Immunology, Emory University School of Medicine, Room 1003, Woodruff Memorial Research Building, 101 Woodruff Circle, Atlanta, Georgia 30322, USA. Phone (404) 727-7310; Fax: (404) 727-7371; E-mail: cweyand@emory.edu.

Yong W. Park's present address is: Department of Rheumatology, Chonnam National University Hospital, Gwangju, South Korea.

Thorsten M. Seyler and Yong W. Park contributed equally to this work.
1. Takemura, S., et al. 2001. Lymphoid neogenesis in rheumatoid synovitis. J. Immunol. 167:1072-1080.

2. Weyand, C.M., Kang, Y.M., Kurtin, P.J., and Goronzy, J.J. 2003. The power of the third dimension: tissue architecture and autoimmunity in rheumatoid arthritis. Curr. Opin. Rheumatol. 15:259-266.

3. de Boer, B.A., et al. 2000. Affinity maturation in ectopic germinal centers. Curr. Top. Microbiol. Immunol. 251:191-195

4. Kang, Y.M., et al. 2002. CD8 T cells are required for the formation of ectopic germinal centers in rheumatoid synovitis. J. Exp. Med. 195:1325-1336.

5. Weyand, C.M., and Goronzy, J.J. 2003. Ectopic germinal center formation in rheumatoid synovitis. Ann. N. Y. Acad. Sci. 987:140-149.

6. Weyand, C.M., Braun, A., Takemura, S., and Goronzy, J.J. 2001. Lymphoid microstructures in rheumatoid synovitis. Curr. Dir. Autoimmun. 3:168-187.

7. Goronzy, J.J., Zettl, A., and Weyand, C.M. 1998. T cell receptor repertoire in rheumatoid arthritis. Int Rev. Immunol. 17:339-363.

8. MacLennan, I., and Vinuesa, C. 2002. Dendritic cells, BAFF, and APRIL: innate players in adaptive antibody responses. Immunity. 17:235-238.

9. Schneider, P., et al. 1999. BAFF, a novel ligand of the tumor necrosis factor family, stimulates B cell growth. J. Exp. Med. 189:1747-1756.

10. Mukhopadhyay, A., Ni, J., Zhai, Y., Yu, G.L., and Aggarwal, B.B. 1999. Identification and characterization of a novel cytokine, THANK, a TNF homologue that activates apoptosis, nuclear factor-kap$\mathrm{paB}$, and c-Jun NH2-terminal kinase. J. Biol. Chem. 274:15978-15981.

11. Shu, H.B., Hu, W.H., and Johnson, H. 1999. TALL-1 is a novel member of the TNF family that is downregulated by mitogens. J. Leukoc. Biol. 65:680-683.

12. Moore, P.A., et al. 1999. BLyS: member of the tumor necrosis factor family and B lymphocyte stimulator. Science. 285:260-263.

13. Mackay, F., and Browning, J.L. 2002. BAFF: a fundamental survival factor for B cells. Nat. Rev. Immunol. 2:465-475.

14. Scapini, P., et al. 2003. G-CSF-stimulated neutrophils are a prominent source of functional BLyS. J. Exp. Med. 197:297-302.

15. Nardelli, B., et al. 2001. Synthesis and release of Blymphocyte stimulator from myeloid cells. Blood. 97:198-204.

16. Gorelik, L., et al. 2003. Normal B cell homeostasis requires $\mathrm{B}$ cell activation factor production by radiation-resistant cells. J. Exp. Med. 198:937-945.

17. Krumbholz, M., et al. 2005. BAFF is produced by astrocytes and up-regulated in multiple sclerosis lesions and primary central nervous system lymphoma. J. Exp. Med. 201:195-200.

18. Craxton, A., Magaletti, D., Ryan, E.J., and Clark, E.A. 2003. Macrophage- and dendritic cell-dependent regulation of human B-cell proliferation requires the TNF family ligand BAFF. Blood. 101:4464-4471.

19. Khare, S.D., et al. 2000. Severe B cell hyperplasia and autoimmune disease in TALL-1 transgenic mice. Proc. Natl. Acad. Sci. U. S. A. 97:3370-3375

20. Mackay, F., et al. 1999. Mice transgenic for BAFF develop lymphocytic disorders along with autoimmune manifestations. J. Exp. Med. 190:1697-1710.

21. Cheema, G.S., Roschke, V., Hilbert, D.M., and Stohl, W. 2001. Elevated serum B lymphocyte stimulator levels in patients with systemic immune-based rheumatic diseases. Arthritis. Rheum. 44:1313-1319.

22. Groom, J., et al. 2002. Association of BAFF/BLyS overexpression and altered $\mathrm{B}$ cell differentiation with Sjögren's syndrome. J. Clin. Invest. 109:59-68. doi:10.1172/JCI200214121.

23. Stohl, W. 2003. SLE--systemic lupus erythemato- sus: a BLySful, yet BAFFling, disorder. Arthritis Res. Ther. 5:136-138.

24. Mackay, F., and Tangye, S.G. 2004. The role of the BAFF/APRIL system in B cell homeostasis and lymphoid cancers. Curr. Opin. Pharmacol. 4:347-354.

25. Hahne, M., et al. 1998. APRIL, a new ligand of the tumor necrosis factor family, stimulates tumor cell growth. J. Exp. Med. 188:1185-1190.

26. Roth, W., et al. 2001. APRIL, a new member of the tumor necrosis factor family, modulates death ligand-induced apoptosis. Cell Death Differ. 8:403-410.

27. Roschke, V., et al. 2002. BLyS and APRIL form biologically active heterotrimers that are expressed in patients with systemic immune-based rheumatic diseases. J. Immunol. 169:4314-4321.

28. Stein, J.V., et al. 2002. APRIL modulates B and $\mathrm{T}$ cell immunity. J. Clin. Invest. 109:1587-1598. doi:10.1172/JCI200215034.

29. Varfolomeev, E., et al. 2004. APRIL-deficient mice have normal immune system development. Mol. Cell. Biol. 24:997-1006.

30. Thompson, J.S., et al. 2001. BAFF-R, a newly identified TNF receptor that specifically interacts with BAFF. Science. 293:2108-2111.

31. Yan, M., et al. 2001. Identification of a novel receptor for B lymphocyte stimulator that is mutated in a mouse strain with severe B cell deficiency. Curr. Biol. 11:1547-1552.

32. von Bulow, G.U., and Bram, R.J. 1997. NF-AT activation induced by a CAML-interacting member of the tumor necrosis factor receptor superfamily. Science. 278:138-141.

33. Gross, J.A., et al. 2001. TACI-Ig neutralizes molecules critical for B cell development and autoimmune disease. Impaired B cell maturation in mice lacking BLyS. Immunity. 15:289-302.

34. Seshasayee, D., et al. 2003. Loss of TACI causes fatal lymphoproliferation and autoimmunity, establish- 
ing TACI as an inhibitory BLyS receptor. Immunity. 18:279-288.

35. Yan, M., et al. 2001. Activation and accumulation of B cells in TACI-deficient mice. Nat. Immunol. 2:638-643

36. von Bulow, G.U., van Deursen, J.M., and Bram, R.J. 2001. Regulation of the T-independent humoral response by TACI. Immunity. 14:573-582.

37. Cao, W., Lee, S.H., and Lu, J. 2005. CD83 is preformed inside monocytes, macrophages and dendritic cells, but it is only stably expressed on activated dendritic cells. Biochem. J. 385:85-93.

38. Liu, Y.J., et al. 1997. Follicular dendritic cells specifically express the long CR2/CD21 isoform. J. Exp. Med. 185:165-170.

39. Cancro, M.P. 2004. Peripheral B-cell maturation: the intersection of selection and homeostasis. Immunol. Rev. 197:89-101.

40. Medema, J.P., Planelles-Carazo, L., Hardenberg,
G., and Hahne, M. 2003. The uncertain glory of APRIL. Cell Death Differ. 10:1121-1125.

41. Schneider, P., et al. 2001. Maturation of marginal zone and follicular B cells requires B cell activating factor of the tumor necrosis factor family and is independent of B cell maturation antigen. J. Exp. Med. 194:1691-1697.

42. Patke, A., Mecklenbrauker, I., and Tarakhovsky, A. 2004. Survival signaling in resting B cells. Curr. Opin. Immunol. 16:251-255.

43. Rahman, Z.S., Rao, S.P., Kalled, S.L., and Manser, T. 2003. Normal induction but attenuated progression of germinal center responses in BAFF and BAFF-R signaling-deficient mice. J. Exp. Med. 198:1157-1169.

44. Klimiuk, P.A., Yang, H., Goronzy, J.J., and Weyand, C.M. 1999. Production of cytokines and metalloproteinases in rheumatoid synovitis is T cell dependent. Clin. Immunol. 90:65-78.
45. Ahonen, C.L., et al. 2004. Combined TLR and CD40 triggering induces potent CD8 $+\mathrm{T}$ cell expansion with variable dependence on type I IFN. J. Exp. Med. 199:775-784.

46. Ye, Q., et al. 2004. BAFF binding to T cell-expressed BAFF-R costimulates $\mathrm{T}$ cell proliferation and alloresponses. Eur. J. Immunol. 34:2750-2759.

47. Zhang, J., et al. 2001. Cutting edge: a role for B lymphocyte stimulator in systemic lupus erythematosus. J. Immunol. 166:6-10.

48. Koyama, T., et al. 2005. Elevated serum APRIL levels in patients with systemic lupus erythematosus [review]. Ann. Rheum. Dis. 8:243-265.

49. van der Valk, P., and Meijer, C.J. 1987. The histology of reactive lymph nodes. Am. J. Surg. Pathol. 11:866-882.

50. Wagner, U.G., et al. 1998. The role of CD8+ CD40L+ $T$ cells in the formation of germinal centers in rheumatoid synovitis. J. Immunol. 161:6390-6397. 